\title{
Quantitative assessment of testicular germ cell production and kinematic and morphometric parameters of ejaculated spermatozoa in the grey mouse lemur, Microcebus murinus
}

\author{
H. Aslam ${ }^{1,4}$, A. Schneiders' ${ }^{2}$, M. Perret ${ }^{3}$, G. F. Weinbauer ${ }^{4}$ \\ and J. K. Hodges ${ }^{2 *}$ \\ ${ }^{1}$ Institute of Reproductive Medicine, University of Muenster, D-48129 Muenster, Germany; \\ ${ }^{2}$ Department of Reproductive Biology, German Primate Centre, D-37077 Goettingen, \\ Germany; ${ }^{3}$ CNRS URA 1183, Laboratoire d Écologie Generale, F-91800 Brunoy, France; \\ and ${ }^{4}$ Covance Laboratories, Kesselfeld 29, 48163 Muenster, Germany
}

Germ cell production and organization of the testicular epithelium in a prosimian species, the grey mouse lemur, Microcebus murinus, was investigated to extend knowledge of comparative primate spermatogenesis. In addition, semen samples collected from adult male lemurs (body weight 53-92 g; $n=16$ ) by rectal probe electroejaculation were evaluated using computer-assisted morphometric and kinematic analysis of spermatozoa. Epididymidal spermatozoa were collected from six animals after hemicastration; the testes were weighed and prepared for stereological analysis and flow cytometry. The relative testis mass (as a percentage of body weight) ranged between 1.17 and $5.6 \%$. Twelve stages of testicular seminiferous epithelium as described for macaques were applied and only a single stage was observed in most of the seminiferous tubule cross-sections. On average (mean $\pm \mathrm{SD}$ ), a single testis contained $1870 \pm$ $829 \times 10^{6}$ germ cells and $35 \pm 12 \times 10^{6}$ Sertoli cells.

\section{Introduction}

Spermatogenesis includes the proliferation of testicular stem cells, meiotic DNA recombination and the highly complex differentiation of round haploid germ cells into mature testicular spermatozoa. Although the types of germ cell involved are similar in all mammals, species-specific differences occur with regard to the number of germ cells, the duration of the spermatogenic process and the topographical arrangement of the spermatogenic stages. Two main distributions of spermatogenic stage arrangement (germ cell associations) have been described: single stage and mixed stage, that is, the presence of one or more spermatogenic stage in a cross-section of the seminiferous tubule. Among primates, spermatogenic variation ranges from predominantly single stage in rhesus (Clermont and Leblond, 1959) and stump-tailed (Clermont and Antar,

*Correspondence

Email: khodges@gwdg.de
Germ cell ratios (preleptotene:type B spermatogonia $=2$, round spermatid:pachytene $=3$; elongated spermatid:round spermatids $=1$ ) indicated high spermatogenic efficacy. Sperm head dimensions and tail lengths of the ejaculated and epididymidal spermatozoa were similar. Percentages of defects (neck/mid-piece and tail) were low $(<10 \%)$ and similar for ejaculated and epididymidal spermatozoa. Spermatozoa were highly motile, characterized by extensive lateral head displacement, but relatively low progressive motility. In conclusion, the grey mouse lemur has unusually large testes with a highly efficient spermatogenic process and large sperm output. These features, together with the high proportion of morphologically normal and highly motile spermatozoa in the ejaculates, indicate that Microcebus murinus is a species in which sperm competition after ejaculation is likely to occur. The predominantly single spermatogenic stage system seems to be an ancestral feature among primates.

1973) macaques, to multiple stages in chimpanzees (Smithwick et al., 1996) and humans (Clermont, 1963; Heller and Clermont, 1964); cynomolgus monkeys (Dietrich et al., 1986) and baboons (Chowdhury and Marshall, 1980) show an intermediate (mixed) form. The physiological significance of this variation is not clear. It was previously thought that the multi-stage arrangement was associated with deficient germ cell production (Sharpe, 1994), but a demonstration of a similar arrangement in the marmoset, a New World species with a highly efficient spermatogenic process, indicates that this might not be the case (Weinbauer et al., 2001). However, this interpretation requires confirmation.

Variation in spermatogenic stage arrangement is also of interest from an evolutionary perspective. If the single stage is the ancestral primate characteristic (it predominates in non-primate species), then mixed associations would appear to have evolved separately (at least) twice (in the Callitrichidae and Hominoidae). Alternatively, if the irregular arrangement appeared early in primate evolution, 
then it has been lost again, at least partially, in some macaques, baboons and most likely other Cercopithecoidea. However, information on quantitative aspects of spermatogenesis in primates representing other lineages is extremely limited and comparable results on nonanthropoid taxa, such as prosimians, have yet to be published.

The principal aim of this study was to extend our knowledge of comparative aspects of primate spermatogenesis by quantitative studies on germ cell production and testicular topography in a prosimian species, the grey mouse lemur, Microcebus murinus. This small malagasy primate is a member of the Cheirogalidae and is of particular interest as it has retained a number of primitive characteristics that place it relatively close to the ancestral primate stock (Martin, 1973; Rumpler et al., 1989; Yoder, 1994; Dutrillaux and Rumpler, 1995; Goodman et al., 1998). Apart from its taxonomic position, reproduction in the grey mouse lemur is characterized by a number of unusual features (Fietz, 1999), which make comparison of testicular function with other primate species interesting. Unlike most species for which detailed physiological data are available, the grey mouse lemur is highly seasonal and has a period of reproductive activity limited to a few weeks followed by complete testicular involution and cessation of spermatogenesis during the non-breeding season (Perret, 1992; Schilling and Perret, 1993). Re-activation of the testes in response to increasing photoperiod is followed by extremely rapid growth to a size (relative to body weight) that far exceeds that of any anthropoid species (Perret, 1992; Kappeler, 1997).

From the behavioural point of view, the mouse lemur is also interesting as it has a multiple-male mating system in which competition for oestrous females can be intense and several males are likely to mate with the same female during a brief period of receptivity (Perret, 1992). Thus, competition between spermatozoa from different males within the female reproductive tract is likely to occur and this, together with a high demand for sperm production (large number of copulations and ejaculations within a limited time period), is probably reflected in the extremely large testes in this species (Harcourt et al., 1981; Dixson, 1995). However, whether, functionally, the testis of the mouse lemur is also characterized by features related to a high production rate of spermatozoa and spermatogenic efficiency is not known. Furthermore, although it has been proposed that sperm competition after mating may be associated with enhanced ejaculate characteristics such as sperm viability, motility and morphology (Møller, 1988), reliable quantitative data on these parameters are limited among primates in general, and detailed information for prosimian species is not available.

Thus, a secondary aim of this study was to provide basic information on ejaculate characteristics in this species using computerized morphometric and kinematic analysis of spermatozoa to generate the first quantitative data on sperm morphology, size and motility patterns.

\section{Materials and Methods}

\section{Animals}

Studies were carried out on 16 adult male grey mouse lemurs (Microcebus murinus), born and maintained at the Institute of Ecology, Brunoy, under controlled conditions as described by Perret (1980, 1992). The males were exposed to a long-day photoperiod (14 h light:10 h dark) for 6-10 weeks before the study commenced to ensure breeding condition in this photoperiod-dependent primate (Perret, 1992). Males were 2-4 years of age, sexually experienced with body weights ranging from 53 to $92 \mathrm{~g}$. Experiments were performed under licence approval (A91.114) and were carried out in accordance with the European Communities Council Directive 89/609/EEC.

\section{Semen collection}

Ejaculates were collected from each male once using rectal probe electroejaculation. Before electroejaculation, each animal was anaesthetized with an i.m. injection of Ketamine/diazepam (100 mg kg-1; Centravet, Plancoet) and placed in lateral recumbancy. A bipolar rectal probe of $4 \mathrm{~mm}$ in diameter consisting of a brass shaft and brass tip with a $1.5 \mathrm{~mm}$ wide plastic ring in between was used. The brass tip was $2 \mathrm{~mm}$ in width. The rectal probe was lubricated with obstetrical gel and inserted approximately $8 \mathrm{~mm}$ into the rectum. The electrical stimulation was performed using an electroejaculator Model 304 ( $p-T$ Electronics, Boring, OR). A switch was placed between the electroejaculator and the rectal probe to administer on/off pulses. Stimulation consisted of pulses of 2-3 s with 10-12 s intervals between pulses starting at $4 \mathrm{~V}$. After about ten pulses the voltage was increased to $5 \mathrm{~V}$. The current did not exceed $10 \mathrm{~mA}$.

Ejaculates were collected in a prewarmed Eppendorf cap. All ejaculates coagulated in the urethra or immediately after emission. No liquefaction occurred and spermatozoa were not released from the coagulum in significant numbers even after incubation in a medium at $37^{\circ} \mathrm{C}$ for several hours. For that reason all coagulums were rinsed with $30 \mu \mathrm{l}$ of a prewarmed $\left(37^{\circ} \mathrm{C}\right)$ TALP medium (Gilchrist et al., 1997) and all further analyses were performed using this sperm suspension. The penis was gently massaged to ensure that no coagulum was left in the urethra.

\section{Tissues and processing}

One testis from six of the animals described above (selected randomly) was removed under Imalgene anaesthesia (100 mg kg-1; Centravet) by scrotal incision. The mass of one testis ranged between 0.5 and $1.5 \mathrm{~g}$ (Table 1). A section of each testis was fixed in Bouin's solution and stored in $70 \%(\mathrm{v} / \mathrm{v})$ ethanol at $4^{\circ} \mathrm{C}$ for stereological analysis. Another section of each testis from each animal was minced finely with dissecting scissors in a solution of PBS buffer (calcium- and magnesium-free), filtered through nylon gauze and stored at $4^{\circ} \mathrm{C}$ for later DNA flow cytometric analysis. 
Table 1. Body weight, testis (single) mass and relative testis mass in individual grey mouse lemurs, Microcebus murinus

\begin{tabular}{lcc}
\hline Body weight $(\mathrm{g})$ & Testis mass $(\mathrm{g})$ & Relative testis mass \\
\hline 81 & 0.8 & 1.97 \\
85 & 0.5 & 1.17 \\
65 & 1.1 & 3.38 \\
86 & 0.8 & 1.86 \\
60 & 0.8 & 2.66 \\
53 & 1.5 & 5.66 \\
\hline
\end{tabular}

aTotal testis mass (single $\times 2$ ) expressed as a percentage of body weight.

\section{Optical disector stereology}

Testes were sliced into three or four equal pieces at right angles to the long axis. The tissue was dehydrated and embedded in resin (hydroxethyl-methacrylate) according to the manufacturer's protocol (Technovit 7100, Heraeus Kulzer $\mathrm{GmbH}$, Wehrheim). Three slices per testis were selected using the systematic uniform random sampling method (Wreford, 1995). Thick sections were cut at $25 \mu \mathrm{m}$ and stained with periodic acid and haematoxylin. Oxidation was carried out in $1 \%(\mathrm{v} / \mathrm{v})$ periodic acid for $30 \mathrm{~min}$. The sections were stained using Schiffs' reagent for 45 min, counterstained with Mayer's haematoxylin for $35 \mathrm{~min}$ and then dipped in Scott's tap water (Sigma Diagnostics, St Louis, MO) for $5 \mathrm{~min}$ to increase the intensity of staining.

The number of germ cells per testis was determined using the optical disector method as previously described (Wreford, 1995; Zhengwei et al., 1998a; Weinbauer et al., 2001). The number of nuclei was assumed to equal the number of cells. Sections were analysed using a $\times 100$ oil immersion lens with numerical aperture of 1.3 on a Zeiss axioscope microscope (Zeiss, Oberkochen) equipped with an ocular net grid and a device to measure the thickness of the section. Fields of view for counting were selected using a systematic uniform random sampling scheme (Gundersen and Jensen, 1987). The upper surface of the section was brought into focus and the first $3 \mu \mathrm{m}$ was disregarded to avoid possible surface imperfections. The next $10 \mu \mathrm{m}$ (depth) was examined focusing through the cell, and the nuclei were counted as they came into focus according to the disector principle (Sterio, 1984). Forty frames corresponding to an area of $6400 \mu \mathrm{m}^{2}$ were evaluated per animal.

The numerical density $\left(N_{V}\right)$ of each type of cell was calculated by dividing the number of cells counted by the volume of all disectors ( $N_{V}=$ number of cells counted/area of frame $\times$ number of frames $\times$ depth). The number of cells per testis was calculated on the basis of $N_{V}\left(N_{V} \times\right.$ testis mass). A ratio of almost 1:1 was assumed between testis mass and volume (Mori and Christensen, 1980). The germ cells were classified as A and B spermatogonia, preleptotene, leptotene and zygotene spermatocytes, pachytene spermatocytes, round spermatids and elongated spermatids, irrespective of the spermatogenic stage. The number of Sertoli cells was also determined in the same manner as that described for the germ cells.

Sections of 3-4 $\mu \mathrm{m}$ in thickness were prepared to analyse the germ cell associations. The seminiferous epithelium was categorized into different stages on the basis of the 12 cellular associations described for the macaque testis (Clermont, 1969). Fifty seminiferous tubules were analysed per testis to determine the frequency of various germ cells. On the basis of these values, the number of germ cells per testis was adjusted to the presence in all stages to calculate the conversion ratios for the various types of germ cell and the germ cell:Sertoli cell ratios.

\section{Flow cytometry}

An ethanol-fixed testicular cell suspension, $10 \mathrm{ml}$, was centrifuged at $300 \mathrm{~g}$ for $5 \mathrm{~min}$. The supernatant was aspirated with a glass jet attached to the aspirator to remove the fixative completely. One millilitre of $0.5 \%(\mathrm{w} / \mathrm{v})$ pepsin solution was added to the pellet before it was incubated for $5 \mathrm{~min}$ at room temperature and then centrifuged at $300 \mathrm{~g}$ for $5 \mathrm{~min}$. After discarding the supernatant, $8 \mathrm{ml}$ 4,6-diamidino2-phenylindole (DAPI) staining solution (DAPI: $5 \mu \mathrm{g} \mathrm{ml}{ }^{-1}$ and sulphorhodamine: $30 \mu \mathrm{g} \mathrm{ml}^{-1}$; Sigma, in Tris buffer) was added to the pellet followed by incubation for $1 \mathrm{~h}$ at room temperature in the dark. The DAPI-stained cells were analysed using the PARTEC II flow cytometer (Partec AG, Muenster) equipped with UV laser. The fluorescent signal was collected using the following filters: KG 1, BG 38 and UG 1 for excitation; TK 420 as dichroic mirror; and GG 435 as barrier filter.

\section{Semen analysis}

Ejaculates were weighed and the sperm suspension evaluated for sperm concentration and live:dead count (WHO, 1992). Computer-assisted sperm analysis (CASA) was performed using the Hobson Sperm Tracker (Hobson Tracking Systems, Sheffield). The settings of the Hobson Tracker were as described by Morrell (1997) and Morrell et al. (1996). Sperm suspensions were diluted further, when necessary, with TALP medium before CASA. Aliquots were placed in a chamber with a depth of $20 \mu \mathrm{l}$, prewarmed to $37^{\circ} \mathrm{C}$ and observed under dark field illumination for motility and kinematic parameters, that is, curvilinear velocity $(\mathrm{VCL})$, straight line velocity (VSL), mean angular displacement (MAD) and linearity (LIN). Smears of the sperm suspension were stained using the Papanicolaou staining method modified for spermatozoa (WHO, 1992). Head length, tail length and total length of spermatozoa were measured using the Hobson morphology program (Hobson Tracking Systems, Sheffield). Morphological classification and identification of sperm defects was carried out according to the criteria outlined in the WHO laboratory manual (1992).

Epididymidal spermatozoa were collected from all six 


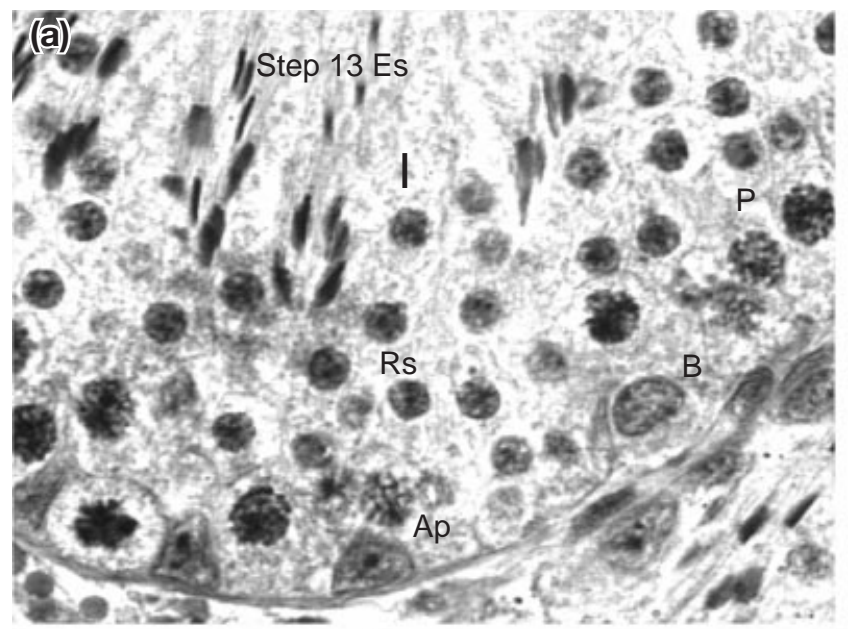

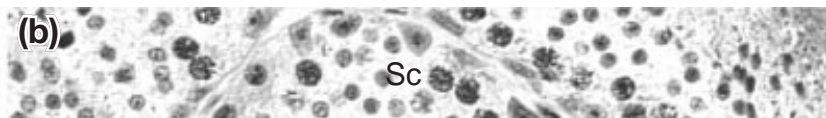

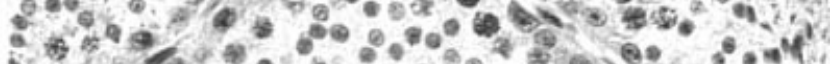
\$. - $50^{\circ}-0^{\circ}, 980^{\circ}$ os $0^{\circ} 0^{\circ}$ 10000.0 -

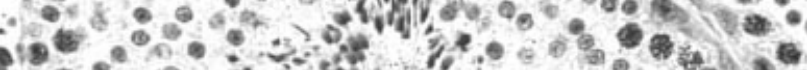

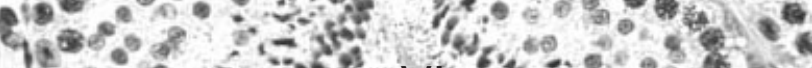

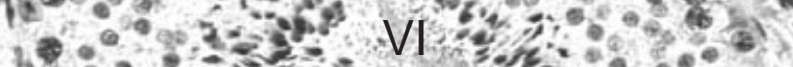

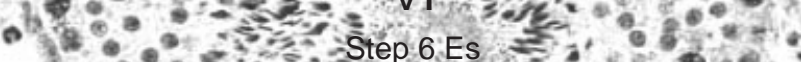

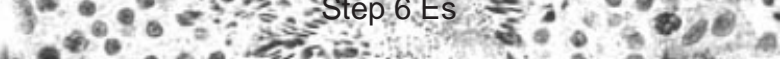

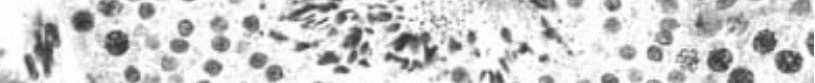

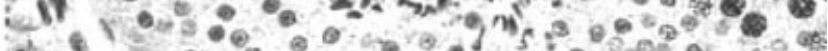

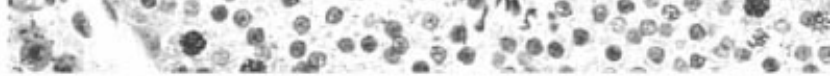
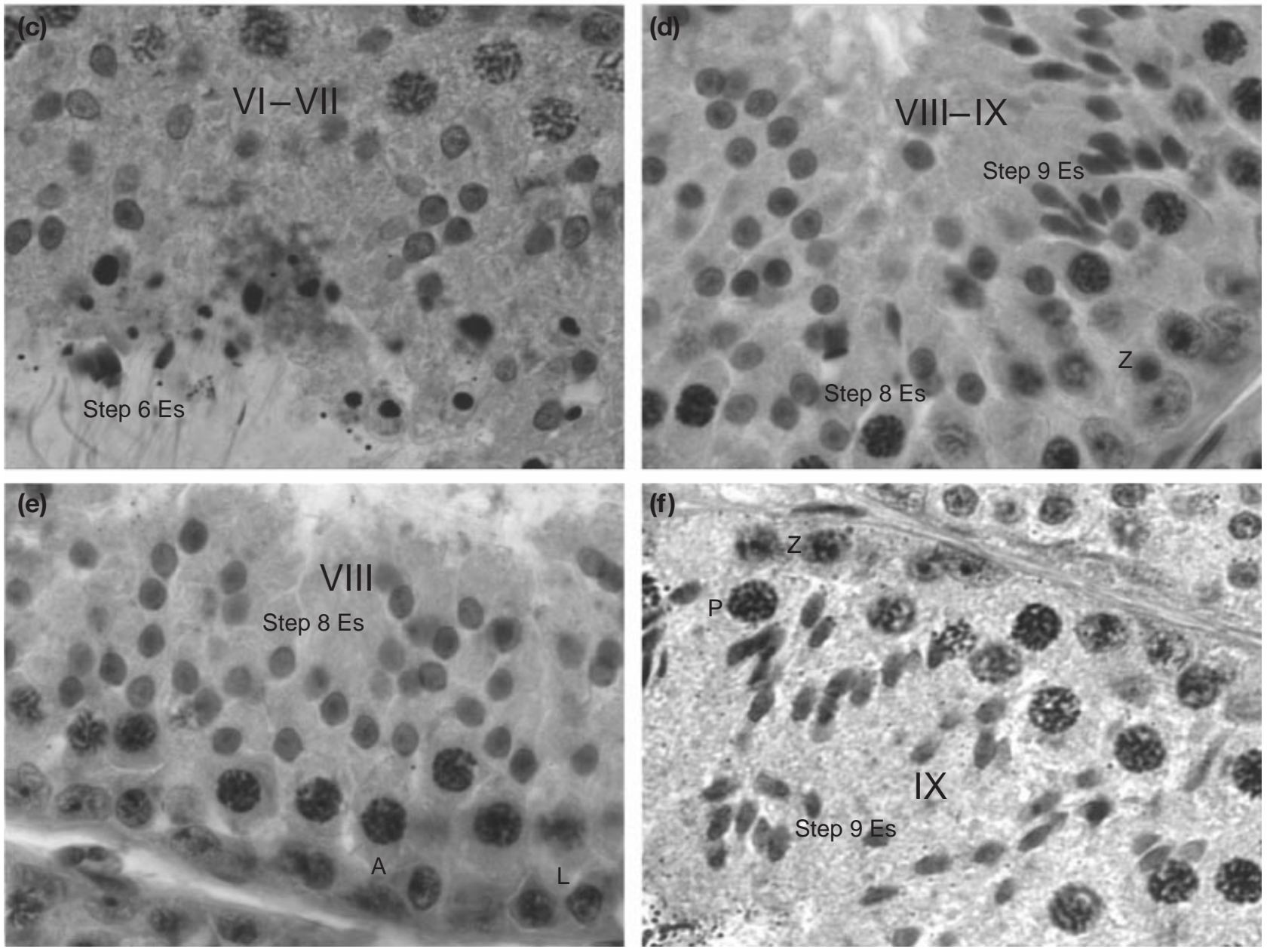

Fig. 1. Micrographs depicting representative stages and types of cells in the seminiferous epithelium of the grey mouse lemur, Microcebus murinus. Roman numerals denote the spermatogenic stage. The stage system of Clermont (1969) as described for macaques was used. Generally, one spermatogenic stage was observed per tubular cross-section. Note the large number of germ cells relative to Sertoli cells in the cross-sections. The developmental/elongation stage of spermatids is indicated by numbered steps. (a) Stage I, step 13 Es; (b) stage VI, step 6 Es; (c) stage VI-VII, step 6 Es; (d) stage VIII-IX, step 9 Es; (e) stage VIII, step 8 Es; and (f) stage IX, step 9 Es. A: type A spermatogonium; Ap: Apale spermatogonium; B: type B spermatogonium; Es: elongating spermatid; L: leptotene spermatocyte, P: pachytene spermatocyte; Rs: round spermatid; Z: zygotene spermatocyte. 
Table 2. Quantification of the number of germ cells and Sertoli cells in the testis of the adult grey mouse lemur, Microcebus murinus

\begin{tabular}{lcc}
\hline Types of cell & Cells per testis $\left(10^{6}\right)$ & GC:SC ratio \\
\hline A & $33 \pm 20$ & $1.1 \pm 0.8$ \\
B & $76 \pm 37$ & $2.1 \pm 0.9$ \\
Pl-Z & $117 \pm 36$ & $3.7 \pm 2.0$ \\
P & $236 \pm 45$ & $7.1 \pm 1.7$ \\
RS & $716 \pm 335$ & $19.8 \pm 6.6$ \\
ES & $692 \pm 473$ & $17.6 \pm 9.5$ \\
RS + ES & $704 \pm 428$ & $19.6 \pm 9.5$ \\
AGC & $1870 \pm 829$ & $51.5 \pm 11.4$ \\
SC & $35 \pm 12$ & - \\
\hline
\end{tabular}

Values are mean \pm SD of six animals.

A: type A spermatogonium; B: type B spermatogonium; PL-Z: preleptotene, leptotene, zygotene spermatocyte; P: pachytene spermatocyte; RS: round spermatid; ES: elongating/elongated spermatid; AGC: all germ cells; GC: germ cell; SC: Sertoli cell.

animals after hemicastration by preparing the ductus deferens and stripping out the spermatozoa. Smears were stained after dilution with TALP medium and analysed for morphology as described above.

\section{Results}

\section{Body weight and testis mass}

Body weights and testis masses (one testis) of six adult mouse lemurs are shown (Table 1). Values for relative testis size, determined by dividing combined testis mass (single testis mass $\times 2$ ) by body weight, ranged between 1.17 and $5.6 \%$ (Table 1$)$.

\section{Testicular organization}

The twelve-stage system of the testicular seminiferous epithelium described for macaques was applied to describe spermatogenesis in the mouse lemur. All germ cell populations were present and spermatogenesis was complete in all animals (Fig. 1). In most preparations examined, seminiferous cross-sections contained one spermatogenic stage. Visual examination of tubule cross-sections revealed small numbers of Sertoli cells compared with germ cells, a finding that was confirmed by quantitative analysis of germ cell:Sertoli cell ratios (see below).

\section{Number of testicular cells and germ cell conversion ratios}

On average, a single testis contained a total of $1870 \pm$ $892 \times 10^{6}$ (mean $\pm \mathrm{SD}$ ) germ cells and $35 \pm 12 \times 10^{6}$ Sertoli cells (Table 2). Germ cells comprised on average $33 \pm 20 \times 10^{6}$ type $A$ and $76 \pm 37 \times 10^{6}$ type B spermatogonia, $117 \pm 36$ and $236 \pm 45 \times 10^{6}$ preleptotene and pachytene spermatocytes, respectively, $716 \pm 335 \times 10^{6}$ (a)

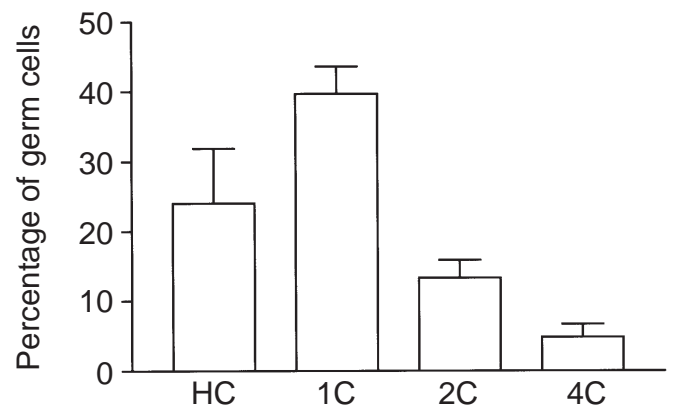

(b)

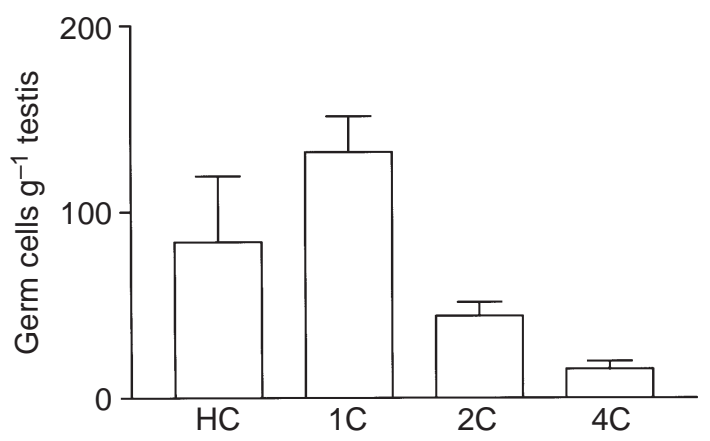

(c)

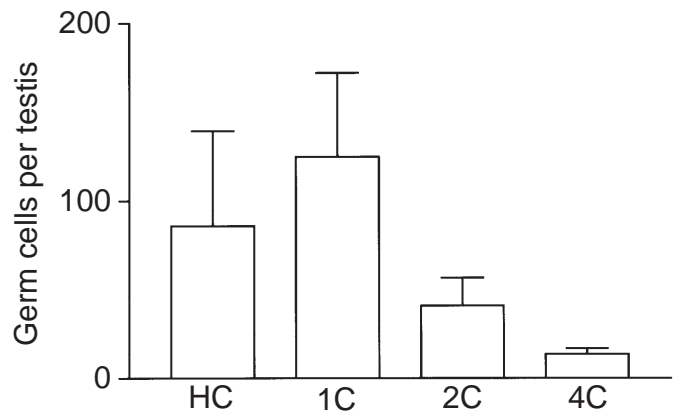

Fig. 2. Flow cytometric analysis of testicular germ cell populations showing (a) the percentage of germ cells, (b) the number of germ cells $\left(\times 10^{6}\right)$ per gram of testis and (c) the number of germ cells $\left(\times 10^{6}\right)$ per testis in the grey mouse leumur, Microcebus murinus. $\mathrm{HC}$ : elongated spermatids ( $\mathrm{H}$ : hypostainability of compacted DNA during spermiogenesis); 1C: round spermatids; 2C: mainly spermatogonia and somatic cells; 4C: tetraploid cells comprising mainly primary spermatocytes and G2 spermatogonia.

round spermatids and $692 \pm 473 \times 10^{6}$ elongating and elongated spermatids. The germ cell conversion ratios, the number of daughter cells resulting from the division of the parent cell, are also shown (Table 3). The ratio of preleptotene, leptotene and zygotene spermatocytes:B spermatogonia was about 2 , indicating that there were four spermatogonial divisions before meiosis. A value of approximately 3 for the round spermatids:pachytene spermatocytes ratio indicated only slight loss of germ cells during meiosis (maximum value 4), whereas the ratio of 1:1 for elongated:round spermatids showed no loss of germ cells during spermatid maturation (Table 3). 
Table 3. Observed and expected conversion ratios (parent and daughter cells) in the testis of the grey mouse lemur, Microcebus murinus

\begin{tabular}{|c|c|c|c|c|c|}
\hline \multirow[b]{2}{*}{ Parent cells } & \multicolumn{5}{|c|}{ Daughter cells } \\
\hline & $\begin{array}{c}\text { Type B } \\
\text { spermatogonia }\end{array}$ & $\begin{array}{c}\text { Preleptotene } \\
\text { spermatocytes }\end{array}$ & $\begin{array}{c}\text { Pachytene } \\
\text { spermatocytes }\end{array}$ & $\begin{array}{c}\text { Round } \\
\text { spermatids }\end{array}$ & $\begin{array}{c}\text { Elongated } \\
\text { spermatids }\end{array}$ \\
\hline $\begin{array}{l}\text { Type A } \\
\text { spermatogonia }\end{array}$ & $\begin{array}{c}4.5 \pm 5.6 \\
(?)\end{array}$ & $\begin{array}{c}5.4 \pm 5.0 \\
(?)\end{array}$ & $\begin{array}{c}11.6 \pm 10.1 \\
(?)\end{array}$ & $\begin{array}{c}35.8 \pm 32.7 \\
(?)\end{array}$ & $\begin{array}{c}40.2 \pm 44.5 \\
\text { (?) }\end{array}$ \\
\hline $\begin{array}{l}\text { Type B } \\
\text { spermatogonia }\end{array}$ & & $\begin{array}{c}1.9 \pm 1.2 \\
(2)\end{array}$ & $3.7 \pm 1.5$ & $\begin{array}{c}11.2 \pm 6.1 \\
(8)\end{array}$ & $\begin{array}{c}10.2 \pm 6.0 \\
(8)\end{array}$ \\
\hline $\begin{array}{l}\text { Preleptotene } \\
\text { spermatocytes }\end{array}$ & & & $\begin{array}{c}2.2 \pm 0.9 \\
(1)\end{array}$ & $\begin{array}{c}7.1 \pm 4.4 \\
(4)\end{array}$ & $\begin{array}{c}7.0 \pm 5.5 \\
(4)\end{array}$ \\
\hline $\begin{array}{l}\text { Pachytene } \\
\text { spermatocytes }\end{array}$ & & & & $\begin{array}{c}3.0 \pm 1.2 \\
(4)\end{array}$ & $\begin{array}{c}2.8 \pm 1.6 \\
(4)\end{array}$ \\
\hline $\begin{array}{l}\text { Round } \\
\text { spermatids }\end{array}$ & & & & & $\begin{array}{l}0.9 \pm 0.5 \\
(1)\end{array}$ \\
\hline
\end{tabular}

Data are mean \pm SD of six animals.

Elongated spermatids include both elongating and elongated spermatids. Expected conversion rates in brackets assume that no germ cells are lost.

Table 4. Ejaculate masses, and numbers and viability of spermatozoa recovered in ejaculates from five adult grey mouse lemurs, Microcebus murinus

\begin{tabular}{|c|c|c|c|c|}
\hline & $\begin{array}{l}\text { Ejaculate masses } \\
\qquad(\mathrm{mg})\end{array}$ & $\begin{array}{l}\text { Total count } \\
\quad\left(\times 10^{6}\right)\end{array}$ & $\begin{array}{l}\text { Live spermatozoa }^{\mathrm{a}} \\
(\%)\end{array}$ & $\begin{array}{c}\text { Motile spermatozoa }{ }^{\mathrm{a}} \\
(\%)\end{array}$ \\
\hline & 52.0 & 0.13 & 69 & 64 \\
\hline & 23.0 & 0.32 & 76 & 50 \\
\hline & 62.0 & 0.12 & 59 & 37 \\
\hline & 82.3 & 0.31 & 63 & 47 \\
\hline & 51.0 & 0.23 & 65 & 44 \\
\hline Mean & $54.06 \pm 21.44$ & $0.22 \pm 0.09$ & $66.40 \pm 6.47$ & $48.40 \pm 9.96$ \\
\hline
\end{tabular}

Values are mean $\pm \mathrm{SD}$.

aThe total count or percentage of live or motile spermatozoa in $30 \mu \mathrm{l}$ rinsed sperm suspension.

\section{DNA flow cytometry}

On the basis of DNA content distribution, flow cytometric analysis of testicular germ cells of the marmoset showed four main peaks: $\mathrm{HC}$ (elongated spermatids; $\mathrm{H}=$ hypostainability of the compacted DNA during spermiogenesis), 1C (round spermatids), 2C (mainly spermatogonia and somatic cells) and 4C (tetraploid cells comprising mainly primary spermatocytes and G2 spermatogonia cells). Testes contained (percentage, mean $\pm \mathrm{SD}$ ) $24 \pm 8 \mathrm{HC}$ cells, $39.7 \pm 41 \mathrm{C}$ cells, $13.3 \pm 32 \mathrm{C}$ cells and $4.8 \pm 24 \mathrm{C}$ cells (Fig. 2). The numbers of germ cells per gram and per whole testis are also shown (Fig. 2).

\section{Ejaculate parameters}

Rectal probe stimulation was successful in yielding an ejaculate in 15 of 16 animals. However, all ejaculates coagulated completely either in the urethra or immediately after release. The mean $( \pm \mathrm{SD})$ mass of the 15 ejaculates was
$45.5 \pm 23.8 \mathrm{mg}$. Of the seven sperm suspensions that contained free spermatozoa, only five specimens contained sufficient numbers of spermatozoa for analysis. The mean $( \pm \mathrm{SD})$ number of spermatozoa in these suspensions was $2.24 \times 10^{5}$ per ejaculate, of which $66.4 \pm 6.4 \%$ were live and $48.4 \pm 9.9 \%$ motile (Table 4 ).

\section{Sperm morphology}

Measurement of dimensions of 30 spermatozoa from each of five animals ( $n=150)$ yielded the following results $(\mu \mathrm{m}$, mean $\pm \mathrm{SD})$ : head length $8.17 \pm 0.19$; tail length $78.48 \pm 1.17$; and total sperm length $86.65 \pm 1.2$ (Fig. 3 ). The head was characterized by the presence of an extended acrosome region (see Bedford, 1974), which was often difficult to visualize and could be measured accurately only in a relatively small proportion of the total number of spermatozoa. Sperm dimensions obtained after rectal probe ejaculation were not significantly different from those obtained directly from the epididymis. The percentages of 


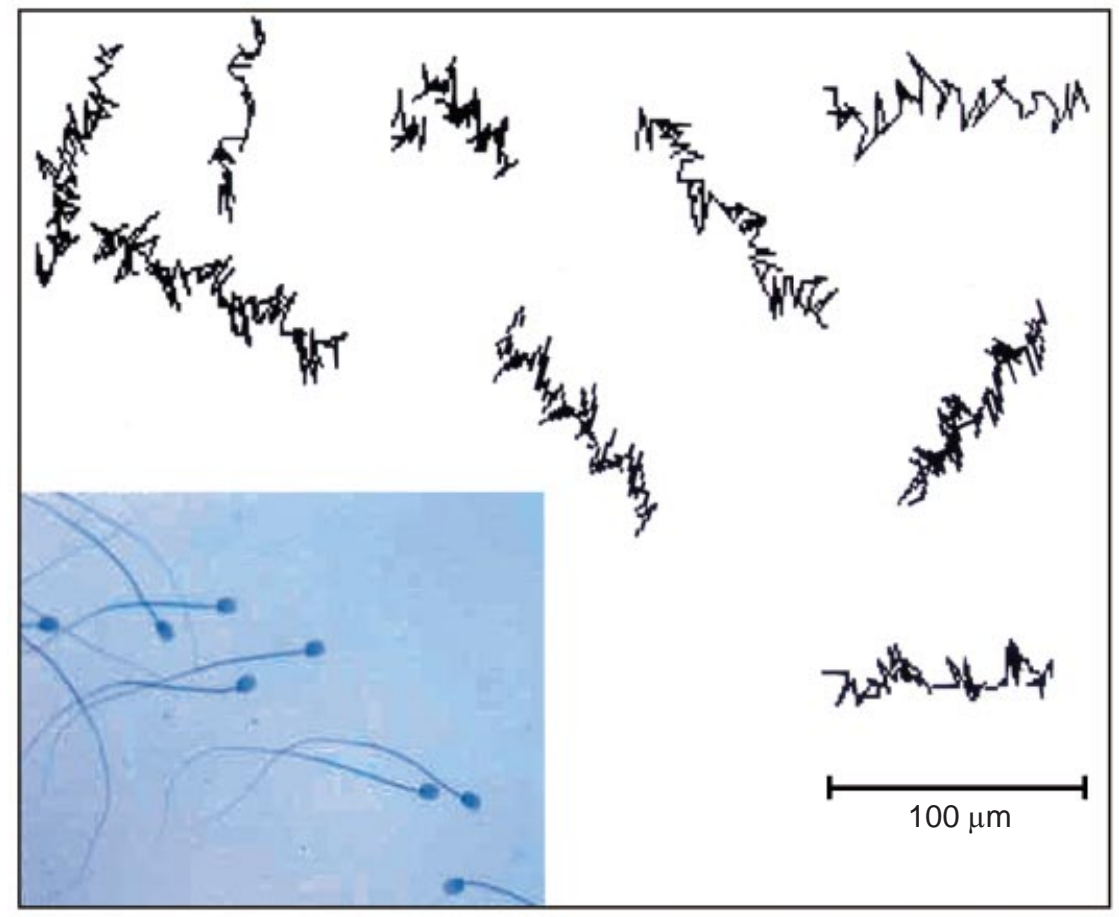

Tracking time: $2 \mathrm{~s}$

Fig. 3. Computerized image of sperm track movement in the grey mouse lemur, Microcebus murinus, indicating the high degree of lateral head displacement. Inset: photomicrograph illustrating the extreme length of the sperm tails.

neck/mid-piece and tail defects were low and were similar for epididymidal and ejaculated spermatozoa (data not shown). No head defects were observed.

\section{Kinematics}

Microcebus spermatozoa were highly motile. Overall, speed of movement was very high with a mean $( \pm \mathrm{SD}) \mathrm{VCL}$ of $145 \pm 83.9 \mu \mathrm{m} \mathrm{s}^{-1}$. The lateral head displacement movement of spermatozoa was also extremely high as shown by a mean MAD value of $87.14 \pm 31.99 \mu \mathrm{m}$. In contrast, values for progressive and linear movement were low. In general, motility was characterized by rapid, high lateral displacement movements with limited progressive (forward) motion (Fig. 3; Table 5).

\section{Discussion}

Relative testes size (expressed as a percentage of body weight) for $M$. murinus ranged from 1.17 to almost $6.0 \%$; values substantially higher than those reported for other primates (for example, $0.27 \%$ for chimpanzees, $0.5-0.8 \%$ for macaques, $0.1 \%$ for gibbons, $0.06-0.1 \%$ for langurs and humans, and $0.05-0.02 \%$ for orang-utans and gorillas: data from Schultz, 1938; Harvey and Harcourt, 1984; Harcourt et al., 1981). The only directly comparable results for prosimians indicate a relative testis size of $0.7 \%$ for the slender loris (Harcourt et al., 1981). Hence, results from the
Table 5. Sperm motility parameters in the grey mouse lemur, Microcebus murinus

Sperm motility parameter

$\begin{array}{ll}\text { Curvilinear velocity }(\mathrm{VCL})\left(\mu \mathrm{m} \mathrm{s}^{-1}\right) & 145.0 \pm 83.95 \\ \text { Straight line velocity }(\mathrm{VSL})\left(\mu \mathrm{m} \mathrm{s}^{-1}\right) & 20.18 \pm 21.07 \\ \text { Linearity }(\mathrm{LIN})(\mathrm{VSL} / \mathrm{VL} \times 100) & 11.81 \pm 10.75 \\ \text { Mean angular displacement }(\mathrm{MAD})\left(^{\circ}\right) & 87.14 \pm 31.99\end{array}$

Values are mean \pm SD.

Five animals and 200 sperm tracks per animal were used.

present study indicate that mouse lemurs are outstanding with regard to relative testis size (Glander et al., 1992); the only species with larger testes is the closely related Cheirogalid, Mirza coquereli (calculations are based on testis volume, Kappeler, 1997). By extrapolation, the testis size of M. murinus would correspond to approximately $0.8 \mathrm{~kg}$ per testis for men.

The stage-related organization of spermatogenesis was similar to that for macaques and usually only one stage of spermatogenesis was applied per tubular cross-section. Hence, the 12-stage classification system originally proposed for rhesus and stump-tailed macaques (Clermont, 1969) was used. In the only study of spermatogenesis in M. murinus, the stage classification system of RoosenRunge and Ortavant was applied (Petter-Rousseaux, 1974). 
However, this system is entirely different from that commonly in use, as stage I is the stage after spermiation, whereas, in Clermont's system, stage $I$ is the stage after completion of the second meiotic division and contains the young spermatids. Hence, a comparison of the present observations on the topography of the germinal epithelium with those of Petter-Rousseaux (1974) is not possible.

The finding of a single spermatogenic stage arrangement, similar to that observed in rodents, provides confirmation that this is the ancestral characteristic among primates. Multiple spermatogenic stages appear to have developed during the course of evolution of the plattyrhines (New World monkeys), although exactly when this characteristic appeared and whether it is present in other non-anthropoid species is not known. The reasons for its initial appearance and subsequent loss in several Old World taxa are also, at present, unclear, but do not appear to be related to mating system or spermatogenic efficiency.

Quantitative analysis of germ cell production for $M$. murinus revealed high spermatogenic efficiency. This high efficiency was evident from the germ cell conversion rates with $>75 \%$ efficiency and the virtual absence of loss of spermatids during spermiogenesis. Petter-Rousseaux (1974) reported six spermatogonial divisions for $M$. murinus. On the basis of the type B:type A spermatogonial ratio of 4.5 and the preleptotene spermatocyte:type B spermatogonium ratio of 1.9 observed in the present study, it is assumed that there are at least three to four spermatogonial divisions. However, as no kinetic studies using tracer or bromodeoxyuridine incorporation into dividing spermatogonia were performed, this requires clarification. Flow cytometry results on the ratio of germ cell populations and the number of cells per unit testis mass complement the stereological findings and further support the high spermatogenic efficiency in M. murinus.

Sertoli cell density in M. murinus is comparatively low among primates. Values obtained in this study were about $12 \times 10^{6}$ Sertoli cells per gram of testicular parenchyma as compared with $26-36 \times 10^{6}$ Sertoli cells per gram of testicular parenchyma in the marmoset (Weinbauer et al., 2001), cynomolgus monkey (Zhengwei et al., 1997, 1998a) and human testis (Zhengwei et al., 1998b). However, the workload of the Sertoli cells in Microcebus, that is, the germ cell:Sertoli cell ratio, is far higher than that for marmosets and men and is closer to that of cynomolgus monkeys.

The precise physiological significance of the different tubule arrangements remains unclear. Of the species investigated so far, humans and marmosets show a multi-stage spermatogenic system, whereas cynomolgus monkeys and mouse lemurs display a single spermatogenic stage; however, all of these species have a similar efficiency of spermatogenesis. Therefore, it is unlikely that topographic arrangement is related to spermatogenic efficiency. However, the results of the present study indicate that the topography of the spermatogenic stages in the primate testis may be associated with the workload of the Sertoli cell. Apparently, Sertoli cells are associated with a higher number of germ cells in testes that show a single stage tubule arrangement compared with those displaying multiple stages. The physiological significance of this occurrence is not entirely clear at present. Microcebus and cynomolgus monkeys display multi-male mating systems, whereas marmosets and humans are usually classified as being predominantly monogamous and occasionally polygynous (Dixson, 1998). However, whether such an association between mating system and Sertoli cell workload can be substantiated requires further analysis in a range of primate species that use different mating strategies.

The results presented here on sperm morphometric and kinematic parameters represent the first quantitative data for a prosimian species. Despite a high success rate in obtaining ejaculates through rectal probe ejaculation, the extent to which coagulation occurred almost immediately precluded collection of information on parameters such as ejaculate volume, total sperm count and live:dead sperm ratios. In terms of their kinematic parameters, Microcebus spermatozoa are unusual in that the high degree of lateral displacement and low progressive motility contrast with characteristics seen in other primate species for which data are available (for example, Yeung et al., 1996; Morrell, 1997). Values for angular (lateral) displacement are 300-400\% of those described for marmoset and macaque monkeys, with a corresponding marked reduction (three- to sevenfold lower) in linear and progressive (forward) motility. The degree to which these findings reflect the physiology of this species or possible artefacts related to entrapment of spermatozoa within the coagulum or to the in vitro conditions used is difficult to ascertain. However, the pattern of sperm motility described here is not unique, but is very similar to that obtained using comparable analytical methods in boars (Holt et al., 1997). Furthermore, the similarly high proportion of morphologically normal spermatozoa in electroejaculates and epididymal samples, together with the high activity of the ejaculated spermatozoa, indicate that the pattern of sperm motility observed here is unlikely to have been altered substantially by the collection procedures used.

The low proportion of spermatozoa with visible defects is also notable. Total defects in ejaculated spermatozoa (12\%) were comparable to those reported for chimpanzees and marmosets, but lower than those described for all other primate species (macaques 18-20\%, Gago et al., 1999; baboons 47\%, Bornman et al., 1988; gorilla > 90\%, Seuanez et al., 1977). The possibility that higher proportions of morphologically abnormal spermatozoa were retained (entrapped) in the coagulum is unlikely, but it cannot be excluded, as it was not possible to recover spermatozoa once the ejaculate had coagulated. However, assuming that the samples analysed are representative, the results indicate that Microcebus is characterized by the production of high quality spermatozoa capable of fertilization (Eggert-Kruse et al., 1996).

In comparison with other primate species, Microcebus spermatozoa are relatively long. Although the measure- 
ments reported in this study (mean length $86.7 \mu \mathrm{m}$ ) are slightly less than that of $92 \mu \mathrm{m}$ (from unspecified literature) reported by Gomendio and Roldan (1991), they are still in the upper range reported for primates (Dixson, 1993). Furthermore, comparison of the results from the present study with our own unpublished results for several callitrichid (including the marmoset monkey) and macaque species, obtained using the same computerized morphometric analysis system, indicates that the larger overall size of Microcebus spermatozoa is primarily attributable to the extended length of the tail. Although the significance of this finding is not clear, it has been postulated that longer spermatozoa are more adaptive in the context of sperm competition. Thus, there is evidence (although somewhat limited) to indicate that males in species with multiple-male mating systems leading to sperm competition (promiscuous mating) produce longer spermatozoa than species in which males usually mate with only one female (Gomendio and Roldan, 1991; Dixson, 1993). The results from the present study are in agreement with this proposal, but they do not support the contention (Gomendio and Roldan, 1991) that there is a positive relationship between sperm length and swimming velocity (at least not in a forward direction). Whether the high degree of lateral movement has any other significance in a sperm competition context is unknown.

Collectively, the results from the present study show that the testicular function in the grey mouse lemur is characterized by high spermatogenic output, probably due to the relatively large numbers of germ cells per unit mass of testicular tissue. The ejaculate appears to be highly fertile, containing a large proportion of morphologically normal, active spermatozoa. These findings, together with the large testes (relative to body weight) in this animal, conform to the pattern predicted for a species in which sperm competition after ejaculation is likely to be prevalent. These results also provide evidence that mating system exerts selective pressures not only on testis size, but also on quantitative aspects of spermatogenic function. The significance of the findings that spermatozoa have unusually long tails but very low progressive motility is not clear, but may be related to vaginal sperm plug formation. The demonstration of a predominantly single spermatogenic stage arrangement indicates that this is probably the ancestral characteristic among primates.

The authors wish to thank E. Nieschlag for his support and cooperation. Technical assistance provided by J. Salzig is gratefully acknowledged. The work was supported by a grant of the German Research Foundation to J. K. Hodges and G. F. Weinbauer.

\section{References}

Bedford JM (1974) Biology of primate spermatozoa Contributions to Primatology 3 97-139

Bornman MS, van Vuuren M, Meltzer DGA, van der Merwe CA and Rensburg SJV (1988) Quality of semen obtained by electroejaculation from chacma baboons (Papio ursinus) Journal of Medical Primatology 17 57-61

Clermont $\mathbf{Y}$ (1963) The cycle of the seminiferous epithelium in man American Journal of Anatomy 112 35-46
Clermont Y (1969) Two classes of spermatogonial stem cells in the monkey (Cercopthecus aethiops) American Journal of Anatomy 126 57-71

Clermont Y and Antar M (1973) Duration of the cycle of the seminiferous epithelium and the spermatogonial renewal in the monkey Macaca aractoides. American Journal of Anatomy 136 153-165

Clermont $\mathbf{Y}$ and Leblond $\mathbf{P}$ (1959) Differentiation and renewal of spermatogonia in the monkey, Macaca rhesus. American Journal of Anatomy 104 237-273

Chowdhury AK and Marshall GR (1980) Irregular pattern of spermatogenesis in the baboon (Papio anubis) and its possible mechanism. In Testicular Development, Structure and Function pp 129-137 Eds A Steinberger and E Steinberger. Raven Press, New York

Dietrich T, Schulze W and Riemer M (1986) Classification of the germinal epithelium in Java monkeys (Macaca cynomolgus) using digital image processing Urologe 25 179-186

Dixson AF (1993) Sexual selection, sperm competition and the evolution of sperm length Folia Primatologica 61 221-227

Dixson AF (1995) Sexual selection and the evolution of copulatory behavior in nocturnal prosimians. In Creatures of the Dark: The Nocturnal Prosimians pp 93-117 Eds L Alterman, G Doyle and K Izard. Plenum Press, New York

Dixson AF (1998) Primate sexuality: comparative studies of the prosimians. In Monkeys, Apes and Human Beings pp 22-49. Oxford University Press

Dutrillaux B and Rumpler Y (1995) Phylogenetic relations among Prosimii with special reference to Lemuriformes and Malagasy Nocturnal. In Creatures of the Dark: The Nocturnal Prosimians pp 93-117 Eds L Alterman, G Doyle and K Izard. Plenum Press, New York

Eggert-Kruse W, Schwarz H, Rohr G, Demirakca T, Tilgen W and Runnebaum B (1996) Sperm morphology assessment using strict criteria and male fertility under in vitro conditions of conception Human Reproduction 11 139-146

Fietz J (1999) Mating system of Microcebus murinus. American Journal of Primatology 48 127-133

Gago C, Pérez-Sánchez F, Yeung CH, Tablado L, Cooper TC and Soler C (1999) Morphological characterization of ejaculated cynomolgus monkey (Macaca fascicularis) sperm American Journal of Primatology 47 105-115

Gilchrist RG, Nayudu PL and Hodges JK (1997) The maturation, fertilization and development of marmoset monkey oocytes in vitro. Biology of Reproduction $\mathbf{5 6} 238-246$

Glander KE, Wright PC, Daniels PS and Merenlender AM (1992) Morphometrics and testicle size of rain forest lemur species from southeastern Madagascar Journal of Human Evolution 22 1-17

Gomendio M and Roldan ERS (1991) Sperm competition influences sperm size in mammals Proceedings of the Royal Society London B 243 181-185

Goodman M, Porter CA, Czelusniak J, Page SL, Schneider H, Shoshani J, Gunnell G and Groves CP (1998) Toward a phylogenetic classification of primates based on DNA evidence complemented by fossil evidence Molecular Phylogenetics and Evolution 9 585-598

Gundersen HJ and Jensen EB (1987) The efficiency of systematic sampling in stereology and its prediction Journal of Microscopy 147 229-263

Harcourt AH, Harvey PH, Larson SG and Short RV (1981) Testis weight, body weight and breeding system in primates Nature 293 55-57

Harvey PH and Harcourt AH (1984) Sperm competition, testes size and breeeding systems in primates Sperm Competition and the Evolution of Animal Mating Systems 18 589-601

Heller CG and Clermont Y (1964) Kinetics of the germinal epithelium in man Recent Progress in Hormone Research 20 545-575

Holt C, Holt WV, Moore HDM, Reed HCB and Curnock RM (1997) Objectively measured boar sperm motility parameters correlate with the outcomes of on-farm inseminations. Results of two fertility trials Journal of Andrology 18 20-23

Kappeler PM (1997) Intrasexual selection and testis size in strepsirhine primates Behavioral Ecology 8 10-19

Martin RD (1973) Adaptive radiation and behaviour of the Malagasy lemurs Philosophical Transactions of the Royal Society London 264 295-352

Møller AP (1988) Ejaculate quality, testes size and sperm competition in primates Journal of Human Evolution 17 479-488 
Mori H and Christensen AK (1980) Morphometric analysis of Leydig cells in the normal rat testis Journal of Cell Biology 84 340-354

Morrell J (1997) CASA as an aid to selecting sperm suspensions for artificial insemination in Callithrix jacchus. International Journal of Andrology 20 287-296

Morrell JM, Nowshari M, Rosenbusch J, Nayudu PL and Hodges JK (1996) Birth of offspring following artificial insemination in the common marmoset, Callithrix jacchus. American Journal of Primatology 41 37-43

Perret M (1980) Influence de la Captivité et du Groupement Social Sur la Physiologie du Microcèbe (Microcebus murinus, Primates) PhD Thesis, University of Paris XI

Perret M (1992) Environmental and social determinants of sexual function in the male lesser mouse lemur (Microcebus murinus) Folia Primatologica 59 1-25

Petter Rousseaux P (1974) Le cycle the I'epithelium seminifere chez Microcebus murinus (Miller, 1777) Mammalia 38 75-87

Rumpler Y, Water S, Ishak B and Dutrillaux B (1989) Chromosomal evolution in prosimians Human Evolution 4 157-170

Schilling A and Perret M (1993) Removal of the olfactory bulbs modifies the gonadal responses to photoperiod in the lesser mouse lemur (Microcebus murinus) Biology of Reproduction 49 58-65

Schultz AH (1938) The relative weight of testes in primates Anatomical Record 72 387-394

Seuanez HN, Carothers AD, Martin DE and Short RV (1977) Morphological abnormalities in spermatozoa of man and great apes Nature 270 345-347

Sharp RM (1994) Regulation of spermatogenesis. In The Physiology of Reproduction pp 1363-1394 Eds E Knobil and JD Neill. Raven Press, New York

Smithwick EB, Young LG and Gould K (1996) Duration of spermatogenesis and relative frequency of each stage in the seminiferous epithelium cycle of the chimpanzee Tissue Cell 28 357-366

Sterio DC (1984) The unbiased estimation of number and sizes of arbitrary particles using the disector Journal of Microscopy 134 127-136

Weinbauer GF, Aslam H, Krishnamurthy H, Brinkworth $\mathrm{MH}$, Einspanier A and Hodges JK (2001) Quantitative analysis of spermatogenesis and apoptosis in the common marmoset (Callithrix jacchus) reveals high rates of spermatogonial turnover and high spermatogenic efficiency Biology of Reproduction 64 120-126

World Health Organization (1992) Laboratory manual for the examination of human semen and semen-cervical mucus interaction. Cambridge University Press, Cambridge

Wreford NG (1995) Theory and practice of stereological techniques applied to the estimation of cell number and nuclear volume in the testis Microscopy Research and Techniques 32 423-436

Yeung $\mathrm{CH}$, Morrell JM, Cooper TG, Weinbauer GF, Hodges JK and Nieschlag E (1996) Maturation of sperm motility in the epididymis of the common marmoset (Callithrix jacchus) and the cynomolgus monkey (Macaca fascicularis) International Journal of Andrology 19 113-121

Yoder AD (1994) Relative position of the Cheirogaleidae in strepsirhine phylogeny: a comparison of morphological and molecular methods and results American Journal of Physical Anthropology 94 25-46

Zhengwei Y, McLachlan RI, Bremner WJ and Wreford NG (1997) Quantitative (stereological) study of the normal spermatogenesis in the adult monkey (Macaca fascicularis) Journal of Andrology 18 681-687

Zhengwei Y, Wreford NG, Schlatt S, Weinbauer GF, Nieschlag E and McLachlan RI (1998a) Acute and specific impairment of spermatogonial development by GnRH antagonist-induced gonadotrophin withdrawal in the adult macaque (Macaca fascicularis) Journal of Reproduction and Fertility 112 139-147

Zhengwei Y, Wreford NG, Royce P, de Kretser DM and McLachlan RI (1998b) Stereological evaluation of human spermatogenesis after suppression by testosterone treatment: heterogeneous pattern of spermatogenic impairment Journal of Clinical Endocrinology and Metabolism 83 1284-1291

Received 2 July 2001.

First decision 21 August 2001.

Revised manuscript received 12 October 2001.

Accepted 23 October 2001. 